\title{
Geomagnetic control of polar mesosphere summer echoes
}

\author{
J. Bremer ${ }^{1}$, P. Hoffmann ${ }^{1}$, T. L. Hansen ${ }^{2}$ \\ ${ }^{1}$ Leibniz-Institut für Atmosphärenphysik, Schloßstr. 6, D-18225 Kühlungsborn, Germany \\ ${ }^{2}$ University of Troms $\varnothing$, The Auroral Observatory, N-9037 Tromsø, Norway
}

Received: 26 May 1999 / Revised: 17 August 1999 / Accepted: 7 September 1999

\begin{abstract}
Using observations with the ALOMAR SOUSY radar near Andenes $\left(69.3^{\circ} \mathrm{N}, 16.0^{\circ} \mathrm{E}\right)$ from 1994 until 1997 polar mesosphere summer echoes (PMSE) have been investigated in dependence on geomagnetic $\mathrm{K}$ indices derived at the Auroral Observatory Tromsø $\left(69.66^{\circ} \mathrm{N}, 18.94^{\circ} \mathrm{E}\right)$. During night-time and morning hours a significant correlation between the signal-to-noise ratio (SNR) of the radar results and the geomagnetic $\mathrm{K}$ indices could be detected with a maximum correlation near midnight. The correlation becomes markedly smaller in the afternoon and early evening hours with a minimum near 17 UT. This diurnal variation is in reasonable agreement with riometer absorption at Ivalo $\left(68.55^{\circ} \mathrm{N}, 27.28^{\circ} \mathrm{E}\right)$ and can be explained by the diurnal variation of ionization due to precipitating high energetic particles. Therefore, a part of the diurnal PMSE variation is caused by this particle precipitation. The variability of the solar EUV variation, however, has no significant influence on the PMSE during the observation period.
\end{abstract}

Key words: Ionosphere (auroral ionosphere) Magnetospheric physics (energetic particles, precipitating) - Radio science (remote sensing)

\section{Introduction}

After the first detection of polar mesosphere summer echoes (PMSE) at Poker Flat, Alaska, in 1979 by Ecklund and Balsley (1981) investigations of this phenomenon have been made with different radars at different places. However even 20 years after the detection of these unexpectedly strong radar echoes at

Correspondence to: J. Bremer altitudes between about $80-90 \mathrm{~km}$, during summer months at polar latitudes, not all the details of this phenomenon are fully understood. Radar scatters from the mesosphere are caused by inhomogeneities in the electron density having spatial scales of about half the radar wavelength. Such small-scale electron density fluctuations are normally smoothed by diffusion. Large charged particles (water cluster ions, aerosols or ice particles) are necessary to reduce the electron diffusivity and maintain these scales as proposed by Kelley et al. (1987). The occurrence of large particles is markedly supported by the low mesospheric temperatures during polar summer months. A detailed review of existing PMSE observations and theories can be found in Cho and Röttger (1997).

Until now there have only been a few investigations concerning the geomagnetic influence upon backscattered mesospheric radar echoes during polar summer conditions. Whereas Rishbeth et al. (1988) reported a connection between geomagnetic field variations and backscattered echo power during one special event, Röttger et al. (1990) did not find such a connection when investigating another PMSE. Using EISCAT observations at $224 \mathrm{MHz}$ in summer 1991 Bremer et al. (1995) estimated a negative correlation between the PMSE occurrence and the geomagnetic $\mathrm{K}$ index of Tromsø.

There are also only very few investigations between PMSE and riometer absorption. These absorption data derived at polar latitudes can be used as a good indicator of enhanced ionization near $80-90 \mathrm{~km}$ (Hargreaves, 1979) due to precipitation of energetic particles. Czechowsky et al. (1989) found a small positive correlation of 0.26 between 240 samples of 30 min mean values of the PMSE peak echo power and corresponding riometer data from observations at Andenes in June 1984.

During the summer months of 1994 to 1997 PMSE observations have been carried out with the ALOMAR SOUSY radar $(53.5 \mathrm{MHz}, 150 \mathrm{~kW}$ peak power, range resolution $300 \mathrm{~m}$, time resolution about $1 \mathrm{~min}$ ) at the 
international ALOMAR facility near Andenes. Details of the ALOMAR observatory are described by von Zahn et al. (1995), and more information about the radar can be found in Singer et al. (1995). In this work the large amount of PMSE data obtained during the 4 years are used to investigate the connection between the backscattered radar echo power (characterized by the signal-to-noise ratio, SNR) and the geomagnetic activity expressed by the 3-h geomagnetic $\mathrm{K}$ values of the Auroral Observatory Tromsø.

\section{Experimental results}

As shown in detail by Hoffmann et al. (1999) the PMSE season at Andenes starts normally near the middle of May and lasts until the end of August. To exclude the strongly variable parts of this seasonal PMSE variation, only the months June and July have been investigated here. In Fig. 1 the daily values of the geomagnetic activity (daily sum of the eight 3 -hourly $\mathrm{K}$ values, $\Sigma \mathrm{K}$ ) and of the solar radio flux F10.7 are presented for the years 1994-1997. The dashed horizontal lines are the mean values of both parameters over the 2-month periods. The geomagnetic and solar activity are rela- tively small with highest mean values in 1994 $(\Sigma \mathrm{K}=24.2, \mathrm{~F} 10.7=78.9)$ and smallest values in $1996 / 97 \quad(\Sigma \mathrm{K}=15.6 / 15.8, \quad \mathrm{~F} 10.7=69.2 / 71.4) . \quad$ The years investigated are relatively near the solar minimum and, therefore, the geomagnetic and solar activity conditions are mostly quiet or only slightly disturbed.

The SNR values of the PMSE used in the correlation analyses are mean values for the height range 83.0 $87.5 \mathrm{~km}$ and 3-hourly intervals according to the geomagnetic $\mathrm{K}$ values. In Fig. 2 one example is shown for the correlation between such mean SNR and the K values for the time interval $0-3 \mathrm{UT}$. Whereas SNR is positively correlated with K (Fig. 2a), between SNR and daily F10.7 values no marked correlation could be found (Fig. 2b). The thick lines are the regression lines calculated from the individual data (circles).

The results of the correlation analyses in dependence on time (UT) are summarized in Fig. 3. In the upper part (Fig. 3a) the correlation coefficients $r(\mathrm{SNR}, \mathrm{K})$ are presented together with the significance levels of $99 \%$ (dotted lines, estimated after Fisher's F-test, for details see Taubenheim 1969), in the lower part (Fig. 3b) the corresponding correlation data r(SNR, F10.7) are shown. Here the results of simple correlation analyses are used instead of partial correlation coefficients
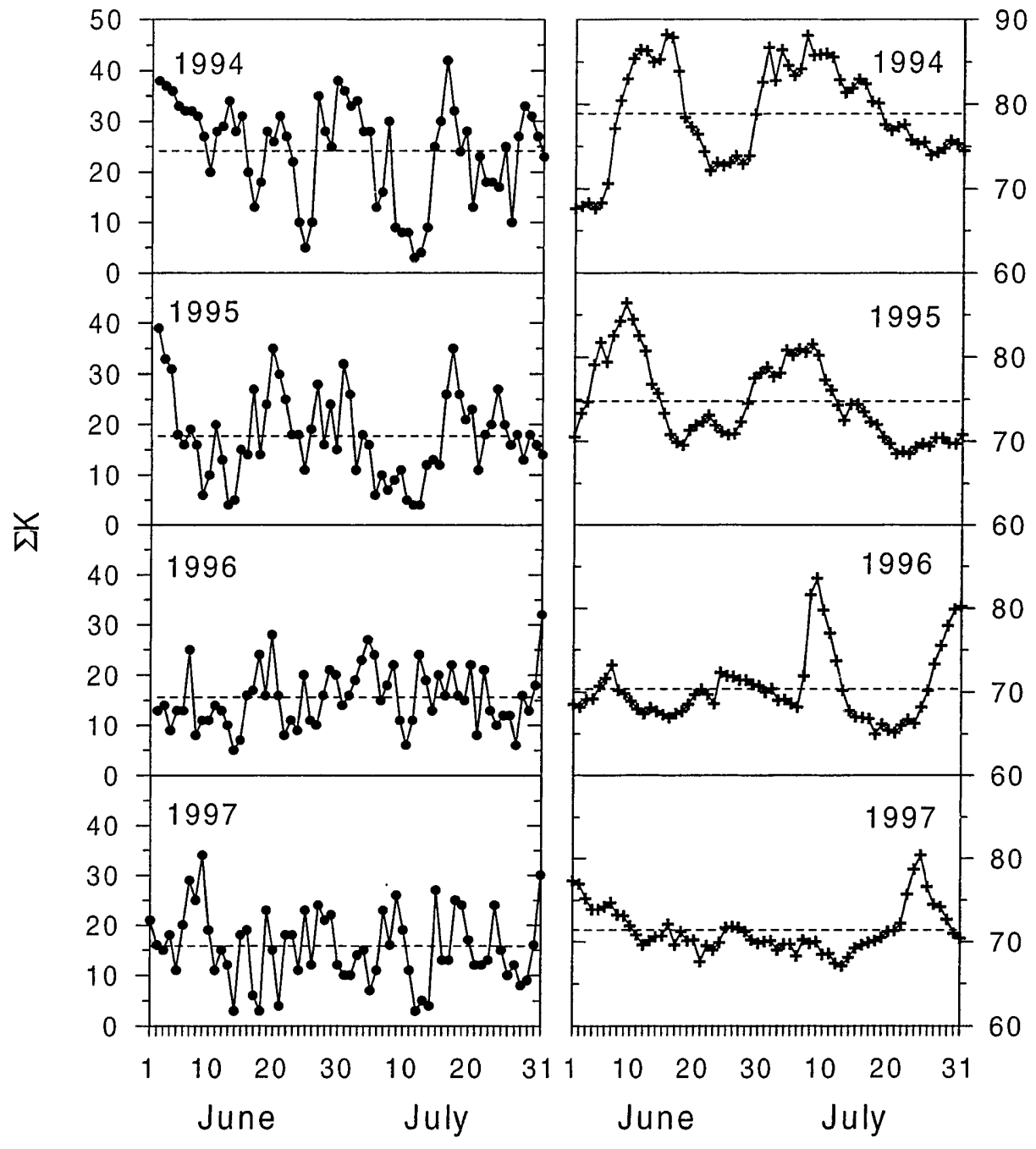

ํㅜㅁ

Fig. 1. Variation of geomagnetic activity (daily sum of eight 3hourly $\mathrm{K}$ values, $\Sigma \mathrm{K}$ ) of Tromsø (left) and of solar $10.7 \mathrm{~cm}$ radio flux (right) for the months June and July 1994-1997. The dashed lines are the mean values for the two-month intervals 

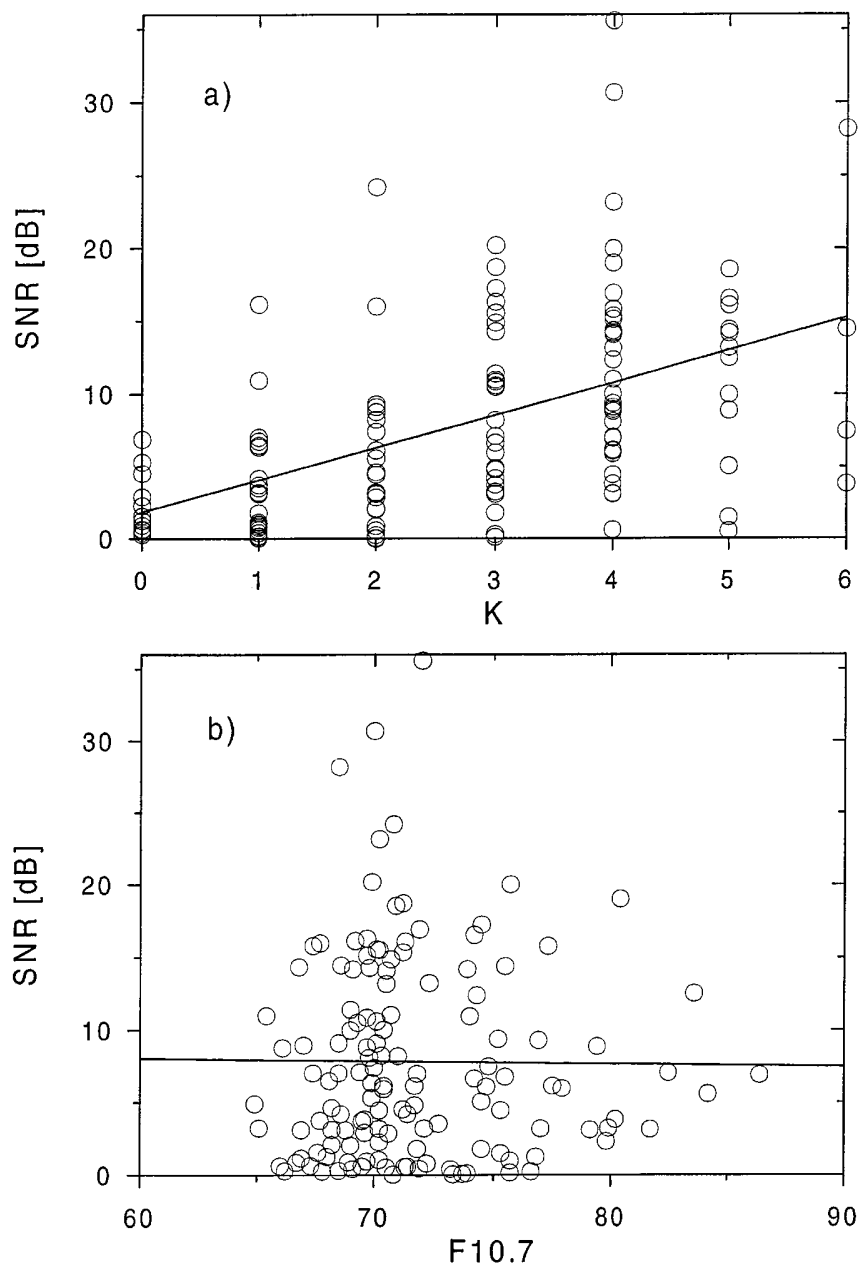

Fig. 2a, b. Dependence of SNR (83.0-87.5 km, Andenes) on a geomagnetic activity $\mathrm{K}$ and $\mathbf{b}$ on solar activity $\mathrm{F} 10.7$ for the time interval 0-3 UT using data for June and July 1994-1997. The straight lines are the regression lines

derived from a twofold regression analysis $\operatorname{SNR}(\mathrm{K}$, F10.7). The results of these different analyses, however, do not differ markedly as the correlation between $\mathrm{K}$ and F10.7 for the investigated time interval is near zero. The correlation between SNR and $\mathrm{K}$ is significant with a reliability of more than $99 \%$ for all time intervals between about 20-12 UT with a maximum correlation near midnight. In the afternoon the correlation becomes markedly smaller with a minimum near 17 UT. The time resolution is not very high due to the 3-hourly time intervals used. In contrast to the correlation between SNR and K, the correlation between SNR and the solar activity index F10.7 is near zero and in all cases not significant (see Fig. 3b).

Another possibility to demonstrate the influence of geomagnetic activity on the diurnal variation of SNR is shown in Fig. 4. The two mean SNR curves in Fig. 4a have been separately calculated from the data of June and July 1994-1997 for low $(\Sigma K<12)$ and high geomagnetic activity $(\Sigma \mathrm{K}>18)$. As to be expected after the correlation results of Fig. 3 the SNR during night and forenoon is clearly higher for geomagnetically disturbed than for quiet conditions. This feature can
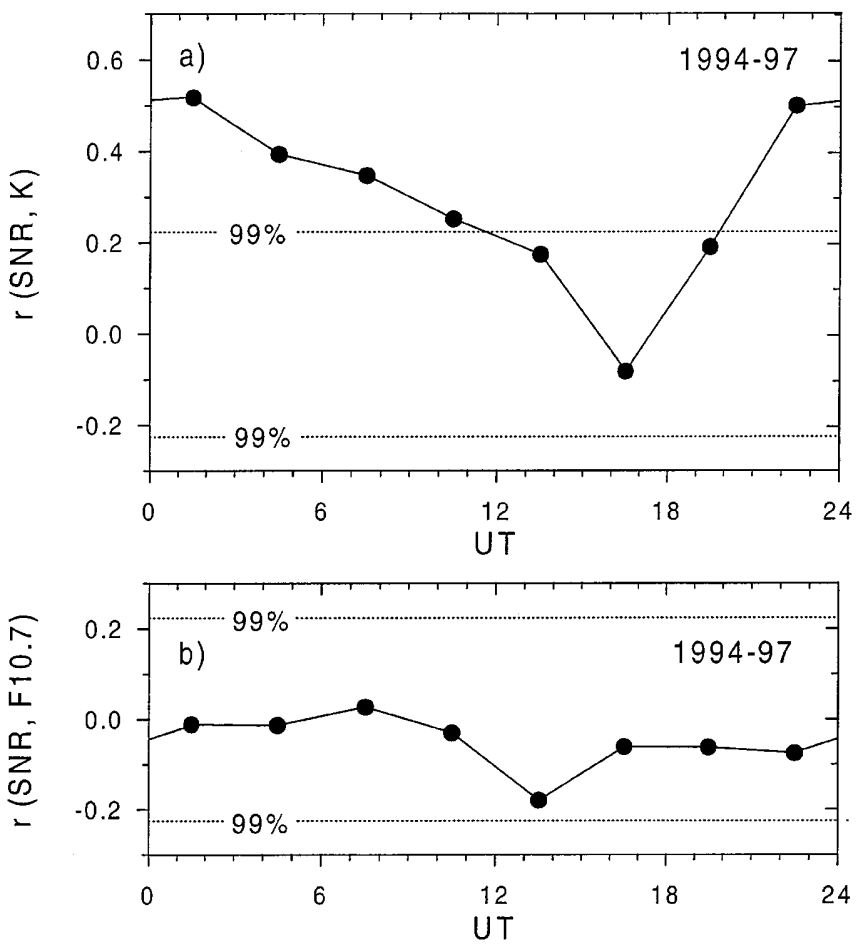

Fig. 3a, b. Diurnal variation of correlation coefficients between a SNR (83.0-87.5 km, Andenes) and geomagnetic $\mathrm{K}$ values and $\mathbf{b}$ between SNR and solar activity indices F10.7 using data for June and July 1994-1997. The dotted lines mark 99\% significance levels

more clearly be seen in Fig. $4 \mathrm{~b}$ where the difference of SNR for disturbed and quiet conditions is shown with a maximum near midnight and a minimum near 17 UT. The shape of this curve is in good agreement with the diurnal variation of the correlation $\mathrm{r}(\mathrm{SNR}, \mathrm{K})$ of Fig. 3a.

\section{Discussion}

As shown in Figs. 3 and 4 the backscattered radar power (SNR) is positively correlated with the geomagnetic activity mainly during nighttime and forenoon. The physical reason for this behaviour should be precipitation events of high energetic particles which are in one case positively connected with the geomagnetic activity and which in the other more often observed during nighttime and in the early morning hours than in the afternoon period. The increasing ionization due to enhanced particle precipitation should then cause stronger backscattered radar echoes. This interpretation is confirmed by simultaneous and common volume PMSE radar measurements and NLC (noctilucent cloud) lidar observations at ALOMAR (von Zahn and Bremer, 1999). Normally an excellent correlation of both phenomena could be found indicating that for both phenomena small ice particles play an essential role. But there are also some cases where NLC have been observed but no PMSE (type 2 after a classification introduced by von Zahn and Bremer, 1999). These cases have mostly been observed near 

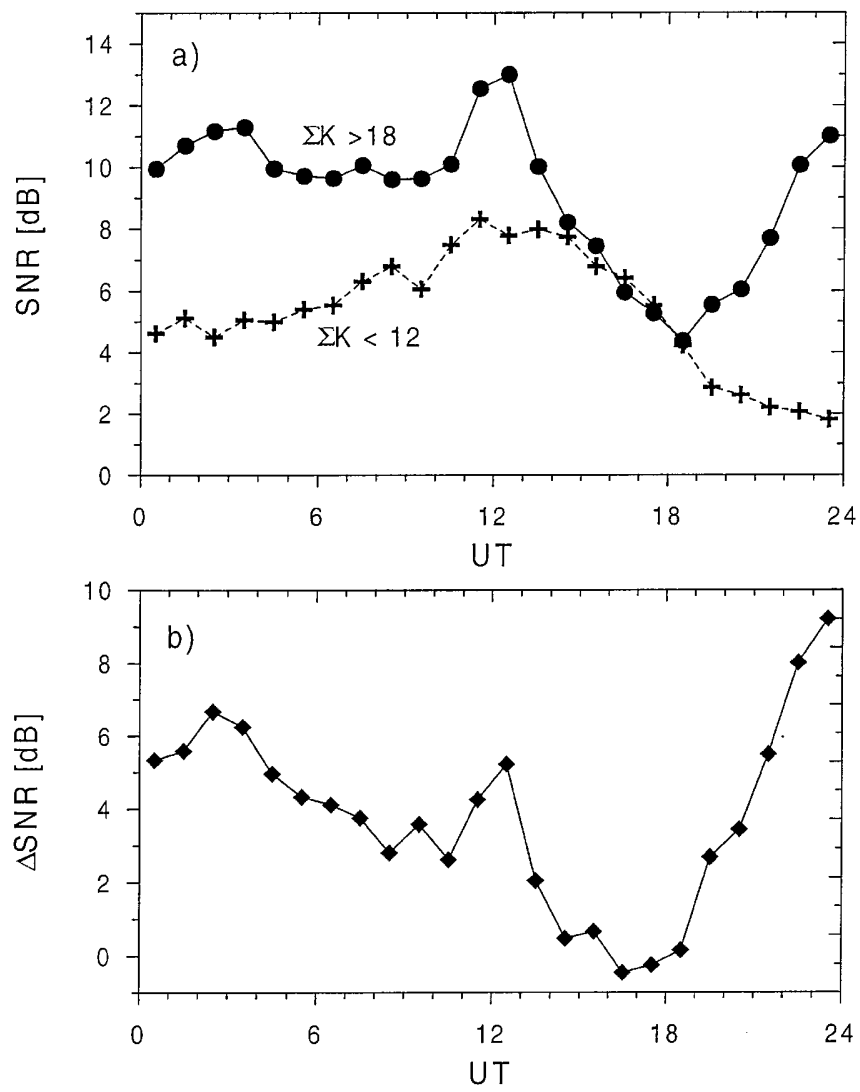

Fig. 4a, b. Mean diurnal variation of SNR (83.0-87.5 km, Andenes) for a two different levels of geomagnetic activity $(\Sigma \mathrm{K}<12$ and $\Sigma \mathrm{K}>18)$ and $\mathbf{b}$ of the difference $\Delta \mathrm{SNR}=\operatorname{SNR}(\Sigma>$ 18) $-\operatorname{SNR}(\Sigma<12)$ using data for June and July 1994-1997

midnight and at very quiet geomagnetic conditions. Here it was assumed that the ionization is too small to create detectable PMSE.

If the diurnal variations shown in Figs. $3 a$ and $4 b$ are mainly caused by precipitating particles then a similar diurnal variation should also be observed in riometer measurements at polar latitudes because it is known from earlier investigations that the cosmic noise absorption (CNA) is a good quantity to describe enhanced ionization due to precipitation of high energetic particles. In Fig. 5 the mean diurnal variation of the cosmic noise absorption CNA at $29.9 \mathrm{MHz}$ is shown for the station Ivalo $\left(68.55^{\circ} \mathrm{N}, 27.28^{\circ} \mathrm{E}\right)$ using all data of June and July 1994-1997. In principle also riometer observations are carried out at Andenes and other stations in northern Europe, but here often only raw data are available and there are no exact absorption values derived from scaled raw data and the undisturbed reference curve (quiet-day curve). For the derivation of representative mean diurnal variations the data of the Finnish riometer chain are very suitable (published in special data bulletins or available via the Internet by the Geophysical Observatory Sodankylä). The diurnal variation of CNA at Ivalo is presented in Fig. 5. To demonstrate that this variation is typical for auroral latitudes near $69^{\circ} \mathrm{N}$ the monthly mean values of Ivalo are compared in Fig. 6 with the data of Kilpisjärvi

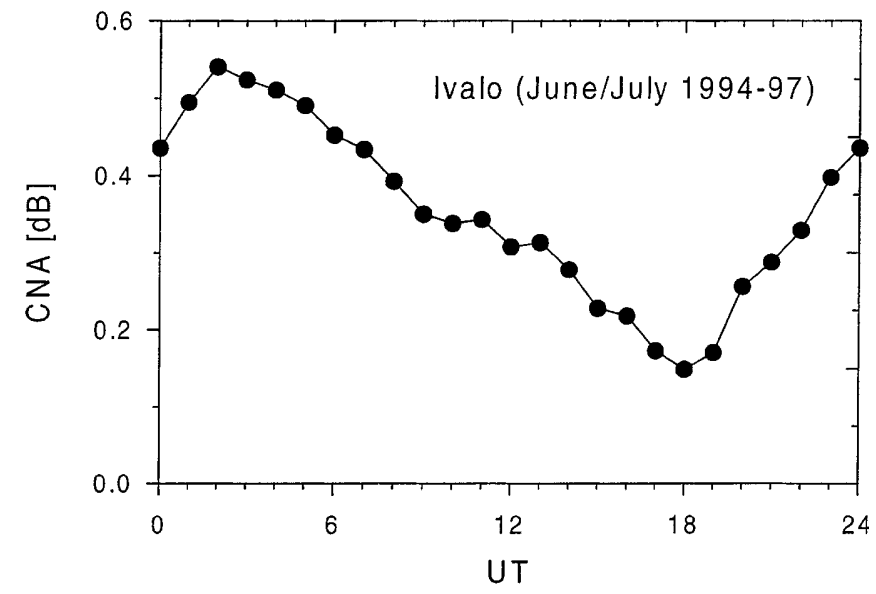

Fig. 5. Mean diurnal variation of cosmic noise absorption (CNA) at 29.9 MHz after observations during June and July 1994-1997 at Ivalo

$\left(69.05^{\circ} \mathrm{N}, 20.78^{\circ} \mathrm{E}\right)$ for June 1994 (unfortunately only data of this month are available from Kilpisjärvi during the period of investigation). The main features of both curves agree quite well, individual differences may be caused by different data gaps in both measurements. The diurnal variation of CNA at Ivalo (Fig. 5, and also at Kilpisjärvi as shown in Fig. 6) is in surprisingly good agreement with the correlation curve in Fig. $3 \mathrm{a}$ and the $\triangle \mathrm{SNR}$ variation in Fig. 4b. Therefore, the diurnal variation of the strength of PMSE is markedly influenced by the diurnal variation of the particle induced ionization. This statement can furthermore be confirmed by CNA variations shown in Fig. 7. In the upper part (Fig. 7a) the mean diurnal CNA variation has been estimated from the observations in June and July 1994 1997 for low $(\Sigma \mathrm{K}<12)$ and high geomagnetic activity

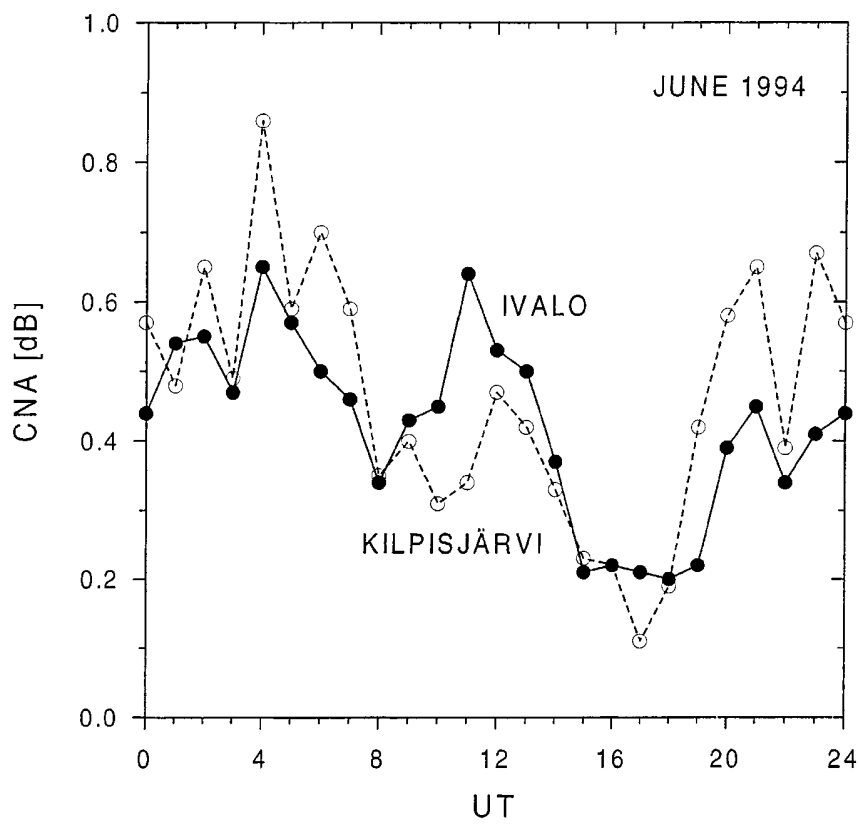

Fig. 6. Mean diurnal variation of CNA at Ivalo (solid curve) and Kilpisjärvi (dashed curve) during June 1994 

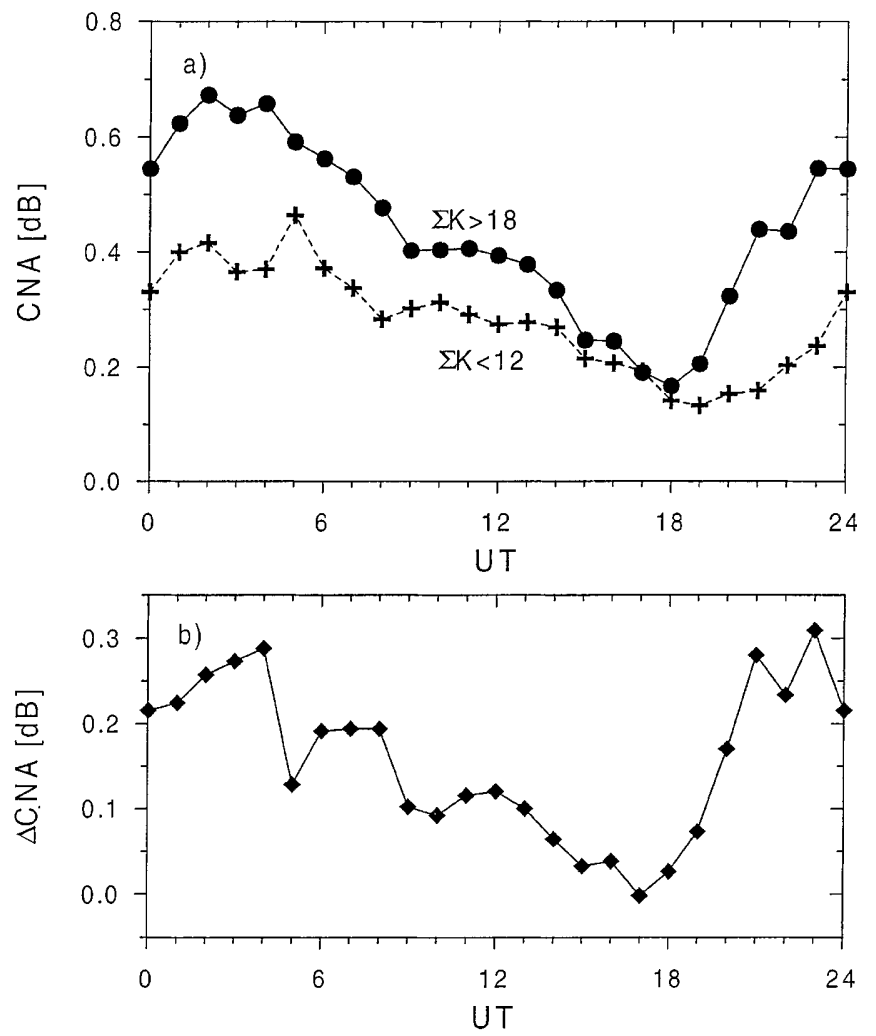

Fig. 7a, b. Mean diurnal variation of CNA at Ivalo for a two different levels of geomagnetic activity $(\Sigma \mathrm{K}<12$ and $\Sigma \mathrm{K}>18)$ and b of the difference $\Delta \mathrm{CNA}=\mathrm{CNA}(\Sigma>18)-\mathrm{CNA}(\Sigma<12)$ using data from June and July 1994-1997

$(\Sigma \mathrm{K}>18)$. The difference between both curves, as presented in Fig. $7 \mathrm{~b}$, agrees rather well with the $\Delta$ SNR curve of Fig. 4b. The connection between SNR and CNA can also be confirmed by correlation calculations between both quantities. One example is shown in Fig. 8 where both data sets for the time interval 0-3 UT are presented with the derived regression line. The correlation coefficient $\mathrm{r}(\mathrm{SNR}, \mathrm{CNA})=0.28$ is not very high but due to the large number of data included $(N=116)$ significant at more than $99 \%$. During the morning hours this correlation increases to 0.37 whereas in the evening hours the correlation becomes markedly smaller and is not significant. The results of Figs. 5-8 confirm the statement given that the PMSE is markedly influenced by particle precipitation.

As derived by Hoffmann et al. (1999) the diurnal variation of PMSE is mainly characterized by a pronounced SNR maximum near 12-13 UT and a clear minimum near 18-20 UT, whereas a more variable secondary maximum near midnight/early morning is detected. This behaviour was also detected by Czechowsky et al. (1989), Kirkwood et al. (1995), and Williams et al. (1995). All these authors tried to find a connection to tidal winds. In a recent paper Hoffmann et al. (1999) demonstrated that a part of this diurnal variation of SNR could be explained by a transport of cold/warm air from polar/equatorial latitudes by tidal wind components. This correlation is significant, but nevertheless the derived correlation coefficients are not very strong (in

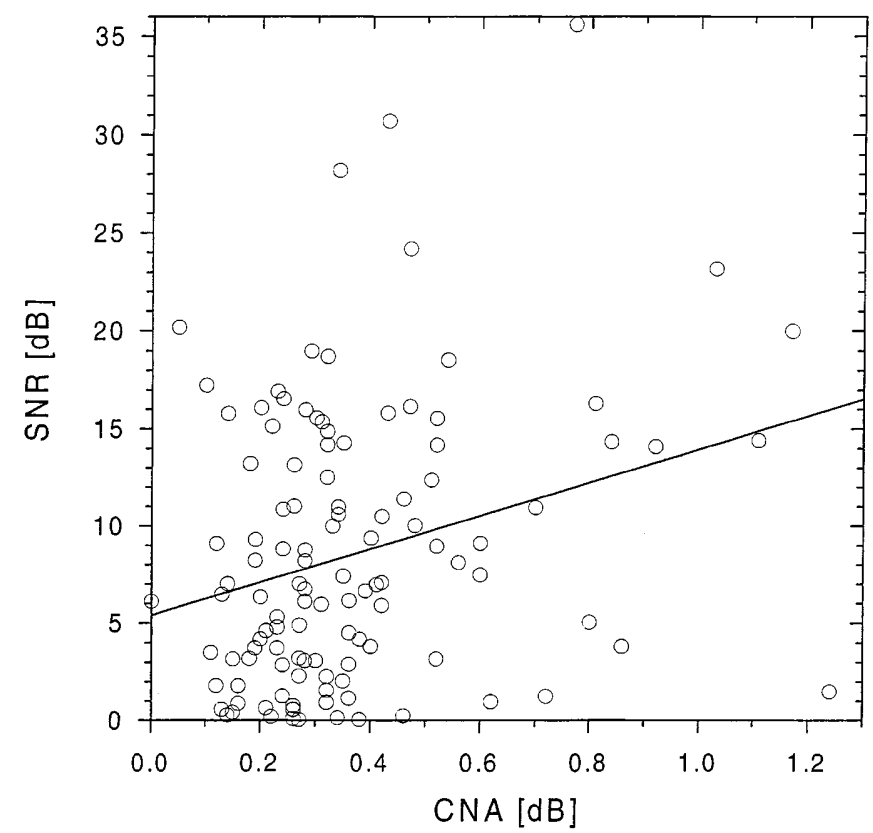

Fig. 8. Dependence of SNR (83.0-87.5 km, Andenes) on CNA (Ivalo) for the time interval 0-3 UT using data from June and July 1994-1997. The straight line is the regression line

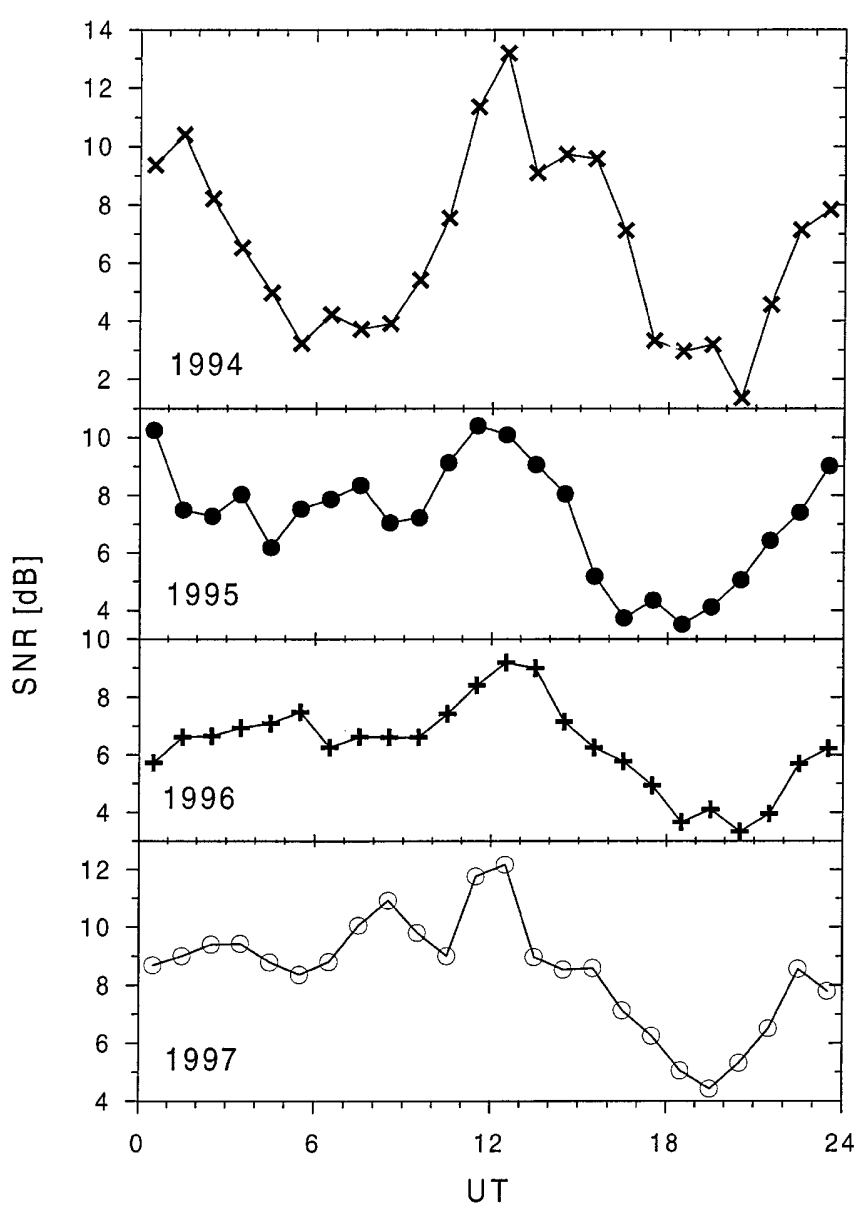

Fig. 9. Diurnal variation of SNR (83.0-87.5 km, Andenes) for the years 1994-1997 with data from June and July 
the order of 0.25 ). One reason of the low correlation may be the influence of the diurnal variation of ionization due to particle precipitation. The results of Fig. 4 confirm this statement. Here the diurnal SNR variation at low geomagnetic activity has nearly no secondary maximum near midnight/early morning whereas at high activity a clear secondary maximum occurs. Similar features can also be found in Fig. 9 where the mean diurnal SNR variations (again for the height range $83.0-87.5 \mathrm{~km}$ ) are presented for the years 1994 until 1997 separately. A clear semidiurnal variation can be seen only during the years with enhanced geomagnetic activity (1994 and 1995). The years with very small activity (1996 and 1997), however, have only a very small secondary maximum during nighttime.

Contrary to the clear geomagnetic effect on the strength of the PMSE no significant influence of solar activity expressed by the solar $10.7 \mathrm{~cm}$ radio flux on PMSE could be found (see Fig. 3b). This result is rather surprising and can only be explained by the fact that the solar activity changes during the years investigated are relatively small with maximum variations between $\mathrm{F} 10.7=65 \ldots 90$. Similar investigations at higher solar activity should be used to verify this result.

Contrary to the results with the ALOMAR SOUSY radar at $53.5 \mathrm{MHz}$ during the years 1994-1997 presented here, Bremer et al. (1995) found a negative correlation between PMSE occurrence after EISCAT VHF radar observations $(224 \mathrm{MHz})$ and geomagnetic activity. A possible explanation of such a negative correlation could be a destruction of heavy water cluster ions by a strong particle precipitation. The EISCAT measurements have been carried out in 1991, a year near the solar activity maximum with clearly stronger geomagnetic disturbances than in the years 1994-1997. Therefore, the investigations of the geomagnetic control of PMSE have to be repeated in future with observations during years at high solar/geomagnetic activity to decide if the detected differences are caused by the levels of geomagnetic activity or by the different radar frequencies used.

\section{Summary and conclusions}

Using observations with the ALOMAR SOUSY radar at Andenes during the summer months June and July 1994 until 1997 the following results could be derived:

1. The signal-to-noise ratio (SNR) of polar mesosphere summer echoes (PMSE) is positively correlated with the geomagnetic activity. The correlation is significant at more than $99 \%$ during time period between about 20 UT and 12 UT with a maximum near midnight. During the afternoon the correlation becomes smaller with a minimum near 17 UT. The reason of this diurnal variation is the variation of ionization due to precipitation of high energetic particles.

2. The diurnal variation of SNR is markedly influenced by the diurnal variation of precipitating particles. In particular the secondary maximum of SNR near midnight/early morning is strongly dependent on geomagnetic activity.

3. The influence of solar activity on PMSE is very small, probably caused by the relatively small activity changes in the years investigated.

Future activities are directed towards repeating such investigations concerning the influence of solar and geomagnetic activity on the structure of polar mesosphere summer echoes.

Acknowledgements. The authors would like to thank H. Bardey, D. Keuer, W. Singer, and M. Zecha for operating the ALOMAR SOUSY radar, the staff of the Andoya Rocket Range for permanent support, and the Geophysical Observatory Sodankylä for riometer data from the stations Ivalo and Kilpisjärvi. The ALOMAR SOUSY radar was a collaboration of the Leibniz-Institut für Atmosphärenphysik, Kühlungsborn, and the Max-Planck-Institut für Aeronomie, Katlenburg-Lindau. The ALOMAR facility is owned and operated by the Andøya Rocket Range.

Topical Editor F. Vial thanks J.Y.N. Cho and P. Chilson for their help in evaluating this paper.

\section{References}

Bremer, J., W. Singer, D. Keuer, P. Hoffmann, J. Röttger, J. Y. N. Cho, and W. E. Swartz, Observations of polar mesosphere summer echoes at EISCAT during summer 1991, Radio Sci., 30, 1219-1228, 1995.

Cho, J. Y. N., and J. Röttger, An updated review of polar mesosphere summer echoes: observation, theory and their relationship to noctilucent clouds and subvisible aerosols, $J$. Geophys. Res., 102, 2001-2020, 1997.

Czechowsky, P., I. M. Reid, R. Rüster, and G. Schmidt, VHF radar echoes observed in the summer and winter polar mesosphere over Andøya, J. Geophys. Res., 94, 5199-5217, 1989.

Ecklund, W. L., and B. B. Balsley, Long-term observations of the Arctic mesosphere with the MST radar at Poker Flat, Alaska, $J$. Geophys. Res., 86, 7775-7780, 1981.

Hargreaves, J. K., The upper atmosphere and solar-terrestrial relations, Van Nostrand Reinhold Company, New York, 1979.

Hoffmann, P., W. Singer, and J. Bremer, Mean seasonal and diurnal variations af PMSE and winds from 4 years of radar observations at ALOMAR, Geophys. Res. Lett., 26, 1521-1524, 1999.

Kelley, M. C., D. T. Farley, and J. Röttger, The effect of cluster ions on anomalous VHF backscatter from the summer polar mesosphere, Geophys. Res. Lett., 14, 1031-1034, 1987.

Kirkwood, S., J. Cho, C. M. Hall, U.-P. Hoppe, D. P. Murtagh, J. Stegman, W. E. Swartz, A. P. van Eyken, G. Wannberg, and G. Witt, A comparison of PMSE and other ground-based observations during the NLC-91 campaign, J. Atmos. Terr. Phys., 57, 35-44, 1995.

Rishbeth, H., A. P. van Eyken, B. S. Lanchester, T. Turunen, J. Röttger, C. Hall, and U.-P. Hoppe, EISCAT VHF radar observations of periodic mesopause echoes, Planet. Space Sci., 36, 423-428, 1988.

Röttger, J., M. T. Rietfeld, C. La Hoz, T. Hall, M. C. Kelley, and W. E. Swartz, Polar mesosphere summer echoes observed with the EISCAT $933 \mathrm{MHz}$ radar and the CUPRI $46.9 \mathrm{MHz}$ radar, their similarity to $224 \mathrm{MHz}$ radar echoes, and their relation to turbulence and electron density profiles, Radio Sci., 25, 761$687,1990$.

Singer, W., D. Keuer, P. Hoffmann, P. Czechowsky, and G. Schmidt, The ALOMAR SOUSY radar: Technical design and further developments, ESA SP-370, 409-415, 1995. 
Taubenheim, J., Statistische Auswertung geophysikalischer und meteorologischer Daten, Akad. Verlagsgesellschaft Geest und Portig K.-G., Leipzig, 1969.

Williams, P. J. S., G. O. L. Jones, J. R. Palmer, and H. Rishbeth, The association of polar mesosphere summer echo layers with tidal modes, Ann. Geophysicae, 13, 454-457, 1995. von Zahn, U., and J. Bremer, Simultaneous and commonvolume observations of noctilucent clouds and polar mesosphere summer echoes, Geophys. Res. Lett., 26, 1525-1528, 1999.

von Zahn, U., E. V. Thrane, and R. Scatteboe, The ALOMAR facility: status and outlook, ESA SP-370, 379-385, 1995. 